\title{
C-X-C motif chemokine ligand 8 promotes endothelial cell homing via the Akt-signal transducer and activator of transcription pathway to accelerate healing of ischemic and hypoxic skin ulcers
}

\author{
LEI SHEN, PENG ZHANG, SHANQIANG ZHANG, LIPING XIE, LIJIE YAO, \\ WEIYA LANG, JIE LIAN, WEI QIN, MENG ZHANG and LIANG JI \\ Department of Anatomy, Qiqihar Medical University, Qiqihar, Heilongjiang 161006, P.R. China
}

Received December 22, 2015; Accepted February 7, 2017

DOI: $10.3892 /$ etm.2017.4305

\begin{abstract}
C-X-C motif chemokine ligand 8 (CXCL-8) promotes cell homing and angiogenesis. However, under hypoxic conditions, the role of CXCL-8 in the homing of human umbilical vein endothelial cells (HUVECs), and its effect on the healing of skin ulcers caused by ischemia and hypoxia remain unknown. In the current study, assays measuring cell proliferation, in vitro angiogenesis and cell migration were performed to evaluate alterations in the proliferation, angiogenic capacity and chemotaxis of HUVECs treated with CXCL-8 protein and/or an Akt inhibitor (AZD5363 group) under hypoxic conditions. Changes in the levels of Akt, signal transducer and activator of transcription 3 (STAT3), vascular endothelial growth factor (VEGF), malondialdehyde (MDA) and total-superoxide dismutase (total-SOD) were also detected by western blotting and ELISA. In addition, in vivo experiments were performed using a skin ulcer model in mice. Ischemic and hypoxic skin ulcers were created on the thighs of C57BL/6J mice, and the effects of CXCL- 8 and HUVEC transplantation on the healing capacity of skin ulcers was determined by injecting mice with HUVECs and/or CXCL-8 recombinant protein (CXCL-8, HUVEC and HUVEC + CXCL-8 groups). Vascular endothelial cell homing, changes in vascular density and the expression of VEGF, SOD, EGF and MDA within the ulcer tissue were subsequently measured. In vitro experiments demonstrated that HUVEC proliferation, migration and tube
\end{abstract}

Correspondence to: Professor Lei Shen, Department of Anatomy, Qiqihar Medical University, 333 Bukui Street, Qiqihar, Heilongjiang 161006, P.R. China

E-mail: shenlei815@yahoo.com

Abbreviations: CXCL-8, C-X-C motif chemokine ligand 8; HUVEC, human umbilical vein endothelial cells; VEGF, vascular endothelial growth factor; SOD, superoxide dismutase; MDA, malondialdehyde; EGF, epidermal growth factor

Key words: hypoxia, C-X-C motif chemokine ligand 8, human umbilical vein endothelial cells, cell homing, skin ulcer forming capacity were significantly increased by CXCL-8 under hypoxic conditions. Additionally, levels of VEGF, MDA and SOD were significantly higher in the CXCL-8 group, though were significantly decreased by the Akt and STAT3 inhibitors. In vivo experiments demonstrated that the expression of VEGF, total-SOD and EGF proteins were higher in the skin ulcer tissue of mice treated with CXCL-8 + HUVEC, relative to mice treated with HUVECs alone. Furthermore, vascular endothelial cell homing and vascular density were significantly increased in the CXCL-8 + HUVEC group, indicating that combined use of HUVECs and CXCL- 8 may promote the healing of ischemic skin ulcers. The present results demonstrate that CXCL-8 may stimulate vascular endothelial cells to secrete VEGF, SOD and other cytokines via the Akt-STAT3 pathway, which in turn serves a key regulatory role in the recruitment of vascular endothelial cells, reduction of hypoxia-related injury and promotion of tissue repair following hypoxic/ischemic injury.

\section{Introduction}

Cardiovascular and cerebrovascular diseases are typically caused by atherosclerosis in the heart, brain and kidney tissues (1). In general, atherosclerosis reduces blood flow, and therefore oxygen supply, to tissues, causing various cell functions to be impaired, such as the vascular endothelial cells $(2,3)$. This frequently leads to the development of severe diseases associated with the cardiovascular system, nervous system, liver, kidney and other tissues and organs, resulting in increased patient mortality rates $(4,5)$. Atherosclerosis and its complications, including heart attack and stroke, are critical public health problems, and diseases caused by hypoxia put major pressure on social health resources (6). Promoting the expansion of blood vessels, use of hyperbaric oxygen and antioxidant treatments are the main strategies currently used to alleviate the effects of hypoxia when secondary to atherosclerosis $(7,8)$, although these methods are exogenous corrective measures and their long-term applications are associated with serious side effects (9). Thus, current therapeutic strategies are limited, and future studies are warranted to identify methods that improve the symptoms of hypoxia and/or promote the recovery of organ function (10). 
Vascular endothelial cells and mesenchymal stem cells (11) have the ability to self-regenerate and thus facilitate the repair of damage tissue; however, hypoxic conditions generally decrease the activity of these cells, resulting in ineffective tissue repair $(12,13)$. Mobilizing endogenous cells to participate in tissue repair may accelerate the recovery of damaged tissues, restore organ functionality and avoid the side effects associated with the use of exogenous drugs $(12,13)$. Identifying improved methods of repairing tissue damage following hypoxic injury is a primary focus of regenerative medical research and may prove useful in the prevention and treatment of vascular diseases.

A lack of blood vessels within a tissue produces a hypoxic environment, leading to decreased biological activity of the surrounding cells. Thus, protecting the anti-hypoxic properties of transplanted cells and improving the local hypoxic environment is a key issue when using cell-based therapies. A previous study of cervical cancer reported that the vascular density of malignant astrocytoma and other tumor tissues decreases as a tumor increases in size, causing hypoxia and other microenvironmental changes (8). In a hypoxic environment, high expression of $\mathrm{C}-\mathrm{X}-\mathrm{C}$ motif chemokine ligand 8 (CXCL-8) may promote tumor cells to secrete interleukin (IL)-6, vascular endothelial growth factor (VEGF) and other inflammatory factors, which regulate vascular endothelial cell homing, accelerate angiogenesis and reduce hypoxia in the tumor microenvironment. This process is associated with the progression and metastasis of tumors (14). Previous results have also demonstrated that CXCL-8 has marked stimulatory effects on cell homing and angiogenesis (15).

Within a hypoxic environment, CXCL-8 interacts with C-X-C motif chemokine receptor (CXCR) 1/2 on the membrane of vascular endothelial cells $(15,16)$. This interaction may promote vascular endothelial cell homing, mobilize cells to participate in the repair of hypoxia-related tissue damage and accelerate angiogenesis (17). However, the effect of CXCL-8 on vascular endothelial cell homing within a hypoxic environment is not well established. Therefore, in the present study, a hypoxic cellular model was used to observe the effects of CXCL-8 on the proliferation, apoptosis and angiogenesis of vascular endothelial cells, and analyze changes in the Akt signaling pathway, VEGF, EGF, total SOD, and MDA. Furthermore, the effects of CXCL-8 on HUVEC homing and the role of CXCL-8 in promoting the healing of ischemic skin ulcers were analyzed in the C57BL/6 J hypoxic mice skin ulcer model to provide a research basis for the recruitment of host cell homing to promote tissue repair.

\section{Materials and methods}

Cell culture and experimental groups. Human umbilical vein endothelial cells (HUVEC/TERT 2) were purchased from the American Type Culture Collection (cat. no. CRL-4053; Manassas, VA, USA). HUVECs were cultured in L-glutamine Dulbecco's modified Eagle's medium (DMEM; Gibco; Thermo Fisher Scientific, Inc., Waltham, MA, USA) supplemented with $10 \%$ fetal bovine serum (FBS; Gibco; Thermo Fisher Scientific, Inc.), $100 \mathrm{U} / \mathrm{ml}$ penicillin and $100 \mathrm{mg} / \mathrm{ml}$ streptomycin (both obtained from Sigma-Aldrich; Merck KGaA, Darmstadt, Germany). Cells were cultured in a hypoxic incubator at $37^{\circ} \mathrm{C}$ with $5 \% \mathrm{CO}_{2}, 3 \% \mathrm{O}_{2}$ and $92 \% \mathrm{~N}_{2}$ mixed gas for $24 \mathrm{~h}$ to produce a cell model of hypoxia, as described previously (18).

A total of $1 \times 10^{6} \mathrm{HUVEC}$ cultured in a normoxic environment at $37^{\circ} \mathrm{C}$ in an atmosphere containing $5 \% \mathrm{CO}_{2}$ for $24 \mathrm{~h}$ were used as a 'normal control group'. HUVECs that were stimulated by $100 \mathrm{ng} / \mathrm{ml}$ recombinant human CXCL-8 protein (cat. no. 208-IL; R\&D Systems, Inc., Minneapolis, MN, USA) at $37^{\circ} \mathrm{C}$ for $24 \mathrm{~h}$ prior to culture in the hypoxic conditions were defined as the 'CXCL-8 group'. An additional group were pre-treated with $6 \mu \mathrm{mol} / 1$ AZD5363 (cat. no. S8019; Akt inhibitor; Selleck Chemicals, Houston, TX, USA) at $37^{\circ} \mathrm{C}$ for $30 \mathrm{~min}$ ('AZD5363 group'), then washed with $0.01 \mathrm{~mol} / \mathrm{l}$ phosphate-buffered saline (PBS) before addition of $100 \mathrm{ng} / \mathrm{ml}$ CXCL-8. HUVECs without any stimulation were used as a 'hypoxia group'.

Cell counting proliferation assay. A total of $3 \times 10^{4}$ HUVECs were harvested for each group and seeded into 96-well plates at $37^{\circ} \mathrm{C}$ for $12 \mathrm{~h}$. The medium was discarded and cells were subsequently washed three times with $0.01 \mathrm{~mol} / 1 \mathrm{PBS}$ and fresh L-glutamine DMEM was added. The cell counting kit-8 (CCK-8) reagent (10 $\mu$; Dojindo Molecular Technologies, Inc., Kumamoto, Japan) was then added to each treatment group at $37^{\circ} \mathrm{C}$ for $4 \mathrm{~h}$. A Multiskan FC microplate photometer (Thermo Fisher Scientific, Inc.) was used to measure the absorbance [optical density (OD) value] at $490 \mathrm{~nm}$ in each group.

DNA fluorescence proliferation assay [5-ethynyl-2'-deoxyuridine (EdU) incorporation assay]. HUVECs were seeded onto glass slides $\left(1 \times 10^{4}\right.$ cells/slide) and cultured in the L-glutamine DMEM at $37^{\circ} \mathrm{C}$ with $5 \% \mathrm{CO}_{2}$ for $24 \mathrm{~h}$. The different experimental treatments were performed (as described above) and, after $12 \mathrm{~h}$ in culture at $37^{\circ} \mathrm{C}, 100 \mu \mathrm{l}$ paraformaldehyde solution (4\%; Sigma-Aldrich; Merck KGaA) was added to cells at room temperature for $30 \mathrm{~min}$. Slides were subsequently incubated with $100 \mu 10.5 \%$ Triton X-100 solution (Sigma-Aldrich; Merck KGaA) at room temperature for $10 \mathrm{~min}$, then with $100 \mu 1$ 1X Apollo reaction liquid (Guangzhou RiboBio Co., Ltd., Guangzhou, China) at room temperature for $30 \mathrm{~min}$ in the dark. Nuclei were stained with $5 \mu \mathrm{g} / \mathrm{ml}$ DAPI (Sigma-Aldrich; Merck $\mathrm{KGaA}$ ) at room temperature for $20 \mathrm{~min}$, mounted using Dako water soluble mounting medium (Dako; Agilent Technologies GmbH, Waldbronn, Germany). A total of 20 fields were observed under the TCS-SP2 laser confocal microscope (Leica Microsystems GmbH, Wetzlar, Germany), the cells with red staining were proliferated cells, and cell proliferation was evaluated using image-Pro Plus 7.0 image analysis software (Media Cybernetics, Inc., Rockville, MD, USA) (19). Cells were washed two to three times with $0.01 \mathrm{~mol} / \mathrm{l}$ PBS (Sigma-Aldrich; Merck) between each step.

Flow cytometry-based apoptosis detection. HUVECs were detached from culture plates using $0.25 \%$ Trypsin-EDTA (HyClone; GE Healthcare Life Sciences, Logan, UT, USA) and washed with $0.01 \mathrm{~mol} / \mathrm{l}$ PBS three times. HUVECs from each group $\left(2 \times 10^{5}\right.$ cells) were resuspended in $200 \mu \mathrm{l}$ Annexin V-fluorescein isothiocyanate (FITC) conjugate solution (1.25\%; Invitrogen; Thermo Fisher Scientific, Inc.) and incubated at room temperature in the dark for $15 \mathrm{~min}$ before 
centrifugation at $4^{\circ} \mathrm{C}$ and $1,000 \mathrm{x} \mathrm{g}$ for $5 \mathrm{~min}$. A total of $200 \mu \mathrm{l}$ propidium iodide (PI) solution (2\%; Invitrogen; Thermo Fisher Scientific, Inc.) was then added and cells were incubated on ice for $2 \mathrm{~min}$. Samples were centrifuged again at $4^{\circ} \mathrm{C}$ and $1,000 \times \mathrm{g}$ for $5 \mathrm{~min}$ and resuspended in $400 \mu \mathrm{l} 0.01 \mathrm{mmol} / \mathrm{l}$ PBS. A BD FACSAria II flow cytometer (BD Biosciences, Franklin Lakes, NJ, USA) was used to detect cell apoptosis. The cell apoptosis numbers were calculated using image-Pro Plus 7.0 image analysis software (Media Cybernetics, Inc.).

Scratch-wound cell migration assay. HUVECs were cultured at $37^{\circ} \mathrm{C}$ for $12 \mathrm{~h}$ in 6 -well cell plates $\left(1.5 \times 10^{6}\right.$ cells/well; Corning Incorporated, Corning, NY, USA) containing HUVEC culture medium supplemented with $0.1 \%$ FBS. The tip of a P1000 pipette was used to create a scratch through the cell monolayer in each group. Hydroxyurea ( $2 \mathrm{mmol} / \mathrm{l}$; Sigma-Aldrich; Merck $\mathrm{KGaA}$ ) was also administered to inhibit cell proliferation. HUVECs were cultured at $37^{\circ} \mathrm{C}$ for $24 \mathrm{~h}$ within a normal or hypoxic environment (as above). Cells were then washed three times with $0.01 \mathrm{~mol} / \mathrm{l} \mathrm{PBS}$, fixed using $4 \%$ paraformaldehyde (Sigma-Aldrich; Merck KGaA) at room temperature for $4 \mathrm{~h}$, and stained with $0.5 \%$ crystal violet (Sigma-Aldrich; Merck $\mathrm{KGaA}$ ). Images of the cells were captured using a BX83 fluorescence microscope (Olympus Corporation). Image-Pro Plus 7.0 software (Media Cybernetics, Inc.) was used to measure the cell scratch area at $0 \mathrm{~h}$ and $24 \mathrm{~h}$, and the wound closure rate was calculated, as previously described (20).

Transwell cell migration assay. HUVECs were cultured at $37^{\circ} \mathrm{C}$ for $24 \mathrm{~h}$ in HUVEC culture medium supplemented with $0.1 \%$ FBS, then $1 \times 10^{4}$ cells were added into the upper compartment of a 25-mm Transwell insert (pore diameter, $8.0 \mu \mathrm{m}$; Corning Incorporated). HUVEC medium (500 $\mu 1,0.1 \%$ FBS) was added into the lower compartment, while according to the experimental grouping, $100 \mathrm{ng} / \mathrm{ml}$ recombinant human CXCL-8 protein and $6 \mu \mathrm{mol} / 1$ AZD5363 (Selleck Chemicals) were administered to cells in the upper compartment. After $8 \mathrm{~h}$ of incubation at $37^{\circ} \mathrm{C}$ in normoxic or hypoxic conditions, cells in the upper compartment were removed, while migrated cells in the lower compartment were washed three times with $0.01 \mathrm{mmol} / \mathrm{l} \mathrm{PBS}$, then fixed with $4 \%$ paraformaldehyde at room temperature for $4 \mathrm{~h}$, stained with $0.5 \%$ crystal violet and imaged using the BX83 microscope. Image-Pro Plus 7.0 software (Media Cybernetics, Inc.) was used to calculate the number of cells and the cell migration rate, as described previously $(20,21)$.

Matrigel tube formation assay. Cultured HUVECs in each experimental group ( $4 \times 10^{5}$ cells) were resuspended in HUVEC culture medium with $0.1 \%$ FBS, then seeded into 8 -well culture plates (Corning Incorporated) pre-coated with cytokine-free Matrigel (BD Biosciences). Cells were cultured at $37^{\circ} \mathrm{C}$ for $12 \mathrm{~h}$ under normoxic or hypoxic conditions and imaged using the BX83 microscope (Olympus Optical Co.) to observe cell morphology. Image-Pro Plus 7.0 software was used to count the number of endothelial cell tubes formed, as described previously (21).

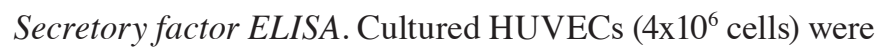
washed three times with $0.01 \mathrm{mmol} / \mathrm{l} \mathrm{PBS}$ and one group of cells was pretreated with $60 \mu \mathrm{mol} / 1 \mathrm{WP1066}$ III, as a specific inhibitor of signal transducer and activator of transcription 3 (STAT3; Santa Cruz Biotechnology, Inc., Dallas, TX, USA), for $30 \mathrm{~min}$ ('WP1066 group'). Cells were then washed three times with $0.01 \mathrm{mmol} / 1 \mathrm{PBS}$, followed by addition of $100 \mathrm{ng} / \mathrm{ml}$ recombinant CXCL-8 to the WP1066 group. Other cell groups were treated according to the experimental groupings described above (normal control, hypoxia model, CXCL-8 and AZD5363 groups), and cells were incubated at $37^{\circ} \mathrm{C}$ for $12 \mathrm{~h}$. The supernatant of each group was collected, filtered using a $0.22-\mu \mathrm{m}$ filter (Corning Incorporated) and stored at $-80^{\circ} \mathrm{C}$ until use.

ELISA kits were used to detect the concentrations of VEGF (cat. no. DVE00; R\&D Systems, Inc.), epidermal growth factor (EGF; cat. no. DEG00; R\&D Systems, Inc.), total superoxide dismutase (total-SOD; cat. no. STA-340; Cell Biolabs, Inc., San Diego, CA, USA) and malondialdehyde (MDA; cat. no. STA-832; Cell Biolabs, Inc.) in the supernatant from each experimental group, according to the manufacturer's protocol. A subset of supernatants was also stored in liquid nitrogen immediately after collection for subsequent western blot analysis to measure the expression of total-SOD, VEGF, MDA, Akt and STAT3.

Animal experiments. A total of 80 male C57BL/6J mice (Animal Center of Qiqihar Medical University, Qiqihar, China), aged 5-8 weeks, and weighing 21-24 g were used in the present study. Mice were housed in an environment at a constant temperature and humidity with a $12 \mathrm{~h}$ light-dark cycle. Mice were provided with free access to food and water. All the mice were administered with $45 \mathrm{mg} / \mathrm{kg}$ pentobarbital (Sigma-Aldrich; Merck KGaA) anesthesia via intraperitoneal injection, and ligation of the femoral artery and its branches near the inguinal ligament and knee joint was performed. A round, full-thickness skin wound with a diameter of $5 \mathrm{~cm}$ was also created on the back of the left thighs to establish an ischemic and hypoxic skin ulcer model, as described previously (22). The mice were divided into four groups; HUVECs $\left(5 \times 10^{5}\right.$ cells) were injected into 40 mice via the tail vein. CXCL-8 (100 ng/ml; $200 \mathrm{mg} / \mathrm{kg}$ ) was injected around the wound on the left limbs of 20 mice; these were used as the CXCL-8 + HUVEC group, and the other 20 mice without drug injection were used as the HUVEC group. For another 20 mice without any HUVECS, CXCL-8 (100 ng/ml; $200 \mathrm{mg} / \mathrm{kg})$ was injected around the wounds on the left limbs, and these were used as the CXCL- 8 group. The same dose of $0.01 \mathrm{~mol} / 1 \mathrm{PBS}$ was injected around the wound on the left limbs of another 20 mice with no HUVECs, and these were used as the PBS control group. The wounds were dressed with Tegaderm transparent dressing ( $3 \mathrm{M}$, Maplewood, MN, USA). Wound healing was observed 7 and 14 days post-surgery, and the wound healing rate was determined using Image-Pro Plus 7.0 software, as described previously (23). All animal experiments were approved by the ethics committee of Qiqihar Medical University.

Skin tissue immunostaining assay. Following 7 days of treatment, 10 mice from each group were randomly selected and anesthetized with $45 \mathrm{mg} / \mathrm{kg}$ pentobarbital via intraperitoneal injection, sacrificed via cervical dislocation and skin tissue 
samples were collected. The sections of the tissues were fixed in $4 \%$ formaldehyde room temperature for $72 \mathrm{~h}$, and tissue samples were harvested from the remaining mice in the same way following 14 days of treatment. Remaining tissues were used in subsequent western blot analysis. Fixed samples were frozen, cut into sections $(50 \mu \mathrm{m})$ and dehydrated in at room temperature in an ethanol gradient $(70,75,80,90$ and $95 \%)$ for $5 \mathrm{~min}$, followed by $100 \%$ ethanol for $10 \mathrm{~min}$ twice. Sections were then sequentially dehydrated in xylene for 10 min twice. Sections were incubated with rabbit anti-human nuclear antigen (hNA; cat. no. ab191181; 1:150; Abcam, Cambridge, $\mathrm{UK}$ ) or rabbit anti-human cluster of differentiation (CD)-31 factor antibody (cat.no. ab76533; 1:200; Abcam) for $12 \mathrm{~h}$ at $4^{\circ} \mathrm{C}$. Sections were subsequently incubated with green fluorescent protein-conjugated goat anti-rabbit immunoglobulin (Ig)-G (cat. no. ab6717; 1:150; Abcam) or rhodamine-conjugated goat anti-rabbit IgG (cat. no. 31670; 1:150; Thermo Fisher Scientific, Inc.) at room temperature for $2 \mathrm{~h}$. Image-Pro Plus 7.0 software was used to measure vessel density and evaluate the extent of vascular endothelial cell homing.

Western blotting. Supernatants from each HUVEC group and mouse skin tissue were preserved in liquid nitrogen. The media was removed and cells or skin tissue were washed twice with ice-cold $0.01 \mathrm{~mol} / 1 \mathrm{PBS}$ and lysed using cell lysis buffer (cat. no. P0013; Beyotime Institute of Biotechnology, Haimen, Zhejiang, China). The lysates were collected by scraping from the plates, and then centrifuged at $10,000 \times \mathrm{g}$ for $5 \mathrm{~min}$ at $4^{\circ} \mathrm{C}$. Total protein quantity was measured using a bicinchoninic acid protein assay kit (cat. no. P0006; Beyotime Institute of Biotechnology) (24). Protein samples $(20 \mu \mathrm{g})$ from cell lysates were resuspended in sample buffer (cat. no. P0015; Beyotime Institute of Biotechnology) containing $62 \mathrm{mM}$ Tris- $\mathrm{HCl}, 2 \%$ SDS, $10 \%$ glycerol, $5 \% \beta$-mercaptoethanol and $0.04 \%$ bromphenol blue, separated by $10 \%$ SDS-PAGE and transferred to nitrocellulose membranes (Bio-Rad Laboratories, Inc.). The membranes were washed once with TBS with $0.1 \%$ Tween-20 (TBST; Sigma-Aldrich; Merck KGaA) and subsequently blocked for $1 \mathrm{~h}$ at room temperature with $5 \%$ skim milk in TBST (25). Blots were incubated with the following primary antibodies: Mouse anti-human VEGF (cat. no. ab11939; 1:200; Abcam), mouse anti-human total-SOD (cat. no. ab66792; 1:150; Abcam), mouse anti-human MDA (cat. no. ab118377; 1:150; Abcam), mouse anti-human Akt (cat. no. ab175354; 1:280; Abcam), mouse anti-human phosphorylated (p)-Akt (cat. no. ab105731; 1:170; Abcam), mouse anti-human STAT3 (cat.no. ab119352; 1:150; Abcam), mouse anti-human p-STAT3 (cat. no. sc-293059; 1:140; Santa Cruz Biotechnology, Inc.) and mouse anti-human GAPDH (cat. no. ab8245; 1:500; Abcam) at $4^{\circ} \mathrm{C}$ overnight. Blots were then incubated with goat anti-mouse horseradish peroxidase-conjugated IgG (cat. no. ab6789; 1:250; Abcam, UK). Protein bands were detected using an enhanced chemiluminescence system (Beyotime Institute of Biotechnology) and Image-Pro Plus 7.0 software was used to quantify the relative OD of each protein band, using GAPDH as an internal reference protein.

Statistical analysis. Data are expressed as the mean \pm standard error of the mean of at least three independent experiments. Analysis of data was performed using SPSS 18.0 software for
Windows (SPSS, Inc., Chicago, IL, USA). Statistical differences between the paired data groups were assessed using independent sample t-tests to generate two-tailed P-values and $\mathrm{P}<0.05$ was considered to indicate a statistically significant difference.

\section{Results}

Effect of CXCL-8 on the proliferation and apoptosis of HUVECs. A CCK-8 assay was performed to assess the proliferation of HUVECs under hypoxic conditions, using the recorded OD values as indicators of proliferative rate. Relative to the HUVEC hypoxia control group, the OD value of the CXCL-8 experimental group was significantly increased by 2.31-fold $(\mathrm{P}<0.01)$. In addition, the OD value of the AZD5363 group was significantly decreased by 0.613 -fold compared with the CXCL-8 group ( $\mathrm{P}<0.01$; Fig. 1A). An EdU incorporation assay also demonstrated that the rate of cell proliferation was significantly increased by 1.617 -fold in the CXCL-8 group, relative to the hypoxia control group $(\mathrm{P}<0.01)$, while the cell proliferation rate in the AZD5363 group was significantly decreased by 0.681 -fold, relative to the CXCL- 8 group $(\mathrm{P}<0.01$; Fig. 1B and $\mathrm{C})$. In addition, FITC-PI flow cytometry demonstrated that the apoptotic rate of HUVECs in the CXCL-8 group was significantly decreased by 0.761 -fold when compared to the hypoxia control group $(\mathrm{P}<0.01)$. Relative to the CXCL-8 group, the apoptotic rate of HUVECs in the AZD5363 group was significantly increased by 1.454 -fold $(\mathrm{P}<0.01$; Fig. 1D and E).

Effects of CXCL-8 on HUVEC migration and tube formation. In a wound scratch assay (Fig. 2A), it was observed that wound closure in the CXCL-8 group was significantly increased by 1.518 -fold, relative to the hypoxia control group $(\mathrm{P}<0.01)$. By contrast, the closure rate of the AZD5363 group was significantly lower $(0.743$-fold $)$ than that observed in the CXCL-8 group ( $\mathrm{P}<0.01$; Fig. 2B). A Transwell assay (Fig. 2C) also demonstrated that the migration rate of HUVECs in the CXCL-8 group was significantly higher (1.587-fold) than that of the hypoxia group $(\mathrm{P}<0.01)$, while the migration rate of the AZD5363 group was significantly decreased by 0.719 -fold, relative to the CXCL- 8 group ( $\mathrm{P}<0.01$; Fig. 2D).

A Matrigel tube formation assay was also performed to evaluate the morphology and tube formation capacity of HUVECs under hypoxic conditions (Fig. 2E). Relative to the normal control group, HUVECs in the CXCL-8 group exhibited a neat arrangement with typical tubular morphology, while those in the hypoxia group exhibited a disordered arrangement with incomplete tube formation. HUVECs in the AZD5363 group also exhibited incomplete tube formation and a dispersed arrangement. The number of HUVEC tubes formed by the CXCL-8 group was significantly higher (3.324-fold) than that in the hypoxia control group $(\mathrm{P}<0.01)$, while the number of tubes formed in the AZD5363 group was significantly lower (0.438-fold) than that in the CXCL-8 group ( $\mathrm{P}<0.01$; Fig. $2 \mathrm{~F})$.

CXCL- 8 affects HUVEC protein expression. Using western blot analysis (Fig. 3A), it was demonstrated that the levels of p-Akt and p-STAT3 in the CXCL-8 group were significantly higher (2.03- and 2.11-fold higher, respectively) than those in 
A

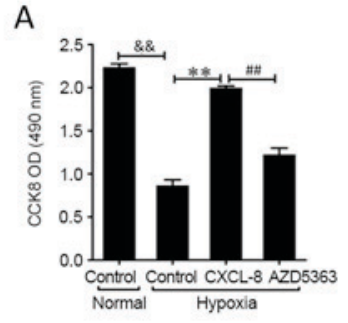

B
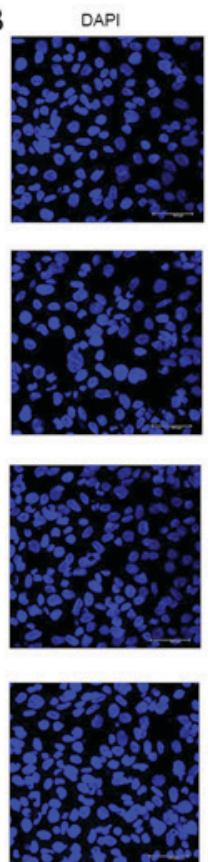

EdU
C
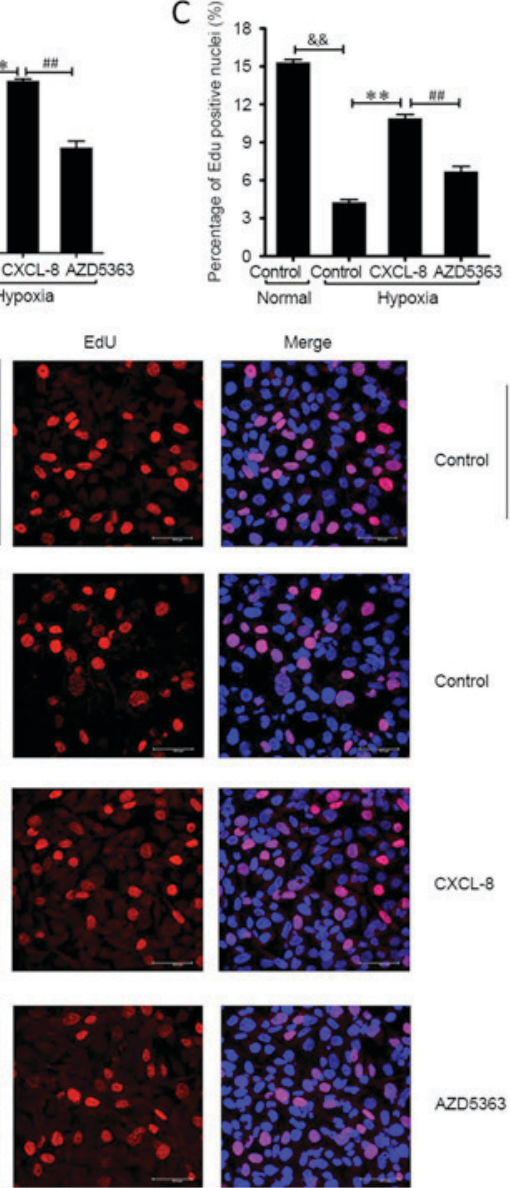

Merge
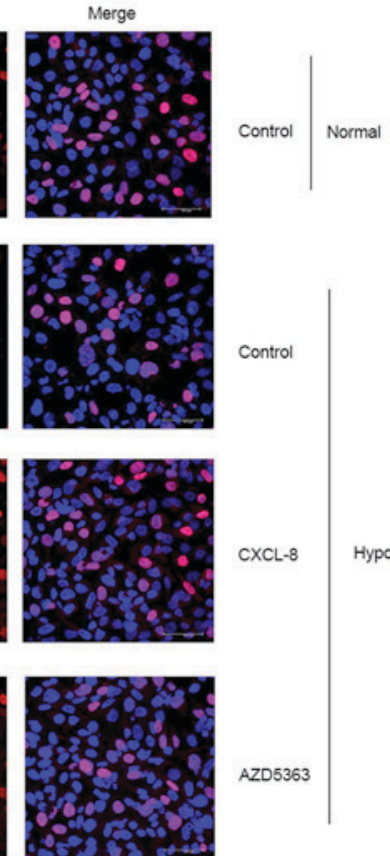

D

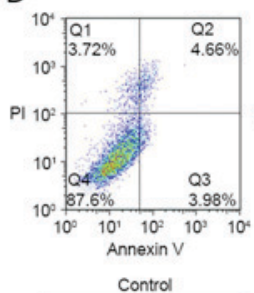

Control

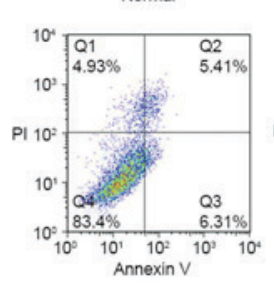

CXCL-8

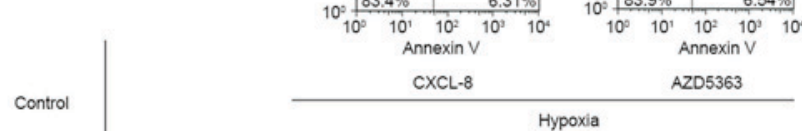

E

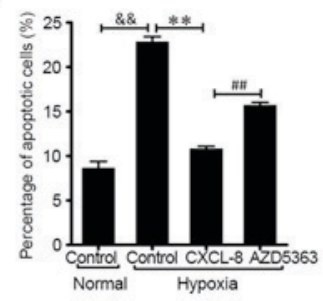

Figure 1. CXCL-8 promotes proliferation and reduces apoptosis of HUVECs during hypoxia. (A) CCK-8 and (B) EdU-incorporation assays measured HUVEC proliferation. (C) Cell numbers of EdU-positive HUVECs (red staining) in each treatment group. (D) Apoptosis of HUVECs measured by flow cytometry. Percentages indicate the proportion of apoptotic cells. (E) Apoptotic rate of HUVECs in each treatment group. ${ }^{\&}$ \& $<0.01$ vs. normal control group; ${ }^{* *} \mathrm{P}<0.01$ vs. hypoxia CXCL-8 group; ${ }^{\# \#} \mathrm{P}<0.01$ vs. hypoxia AZD5363 group. Data are expressed as the mean \pm standard error of the mean ( $\mathrm{n}=18$ ). $\mathrm{CXCL}-8, \mathrm{C}-\mathrm{X}-\mathrm{C}$ motif chemokine ligand 8; HUVEC, human umbilical vein endothelial cell; CCK-8, Cell Counting Kit-8; OD, optical density; CCK-8, Cell Counting Kit-8 EdU, 5-ethynyl-2'-deoxyuridine; AZD5363, Akt inhibitor.

the hypoxia group $(\mathrm{P}<0.01)$. In the AZD5363 group, levels of p-Akt and p-STAT3 were significantly lower (0.37- and 0.53 -fold, respectively) than those in the CXCL-8 group $(\mathrm{P}<0.01$; Fig. 3B and $\mathrm{C})$.

To determine whether the effects of CXCL-8 on HUVECs were mediated by Akt signaling, HUVECs were treated with a STAT3 inhibitor (WP1066 group) prior to culture under hypoxic conditions. Results of ELISA experiments indicated that the levels of total-SOD, VEGF and EGF in the CXCL-8 group were significantly higher (3.208-, 3.044- and 2.545-fold, respectively) than in the hypoxia control group $(\mathrm{P}<0.01)$. Relative to the CXCL- 8 group, levels of total-SOD, VEGF and EGF in the AZD5363 group were significantly decreased (0.804-, 0.406- and 0.653-fold, respectively; $\mathrm{P}<0.01$ ). In addition, relative to the CXCL- 8 group, levels of total-SOD, VEGF and EGF in the WP1066 group were significantly decreased (0.530, 0.293 and 0.429-fold, respectively; P<Fig. 3D-F). Furthermore, the concentration of MDA in the culture supernatant of the CXCL-8 group was significantly lower (0.644-fold) than that in the hypoxia control group $(\mathrm{P}<0.01)$, whereas levels of MDA in the AZD5363 and WP1066 groups were significantly increased (1.295- and 1.204-fold, respectively) relative to the CXCL-8 group (both $\mathrm{P}<0.01$; Fig. $3 \mathrm{G}$ ).
CXCL-8 promotes the healing of hypoxic skin ulcers. In a rat model of hypoxic skin ulcers, it was demonstrated that the healing rate of ulcers in the CXCL- 8 + HUVEC group was significantly increased, relative to groups treated with CXCL-8 or HUVEC alone $(\mathrm{P}<0.01$; Fig. 4). Immunofluorescence staining of the ulcer tissue on days 7 and 14 after surgery demonstrated that vascular density was significantly higher in the CXCL-8 + HUVEC group than in the CXCL-8 or HUVEC groups $(\mathrm{P}<0.01$; Fig. $5 \mathrm{~A}-\mathrm{C})$. On day 7 post-surgery, hNA staining was significantly increased in the CXCL-8 + HUVEC group relative to the HUVEC group ( $\mathrm{P}<0.01$; Fig. 5D and $\mathrm{E})$, indicating a greater extent of vascular endothelial cell homing in the CXCL-8 + HUVEC group.

CXCL-8 affects the expression of VEGF, EGF, total-SOD and MDA in hypoxic skin ulcers. In the hypoxic skin ulcer tissue of the CXCL-8 + HUVEC group, it was observed that the levels of total-SOD, VEGF and EGF were significantly increased by 2.473-, 1.542- and 1.255-fold, respectively, relative to the HUVEC control group ( $\mathrm{P}<0.01$; Fig. $6 \mathrm{~A}-\mathrm{F})$. In addition, MDA expression in the ulcer tissue of the CXCL- $8+$ HUVEC group was significantly higher (0.778-fold) than in the HUVEC group $(\mathrm{P}<0.01$; Fig. $6 \mathrm{G}$ and $\mathrm{H})$. 


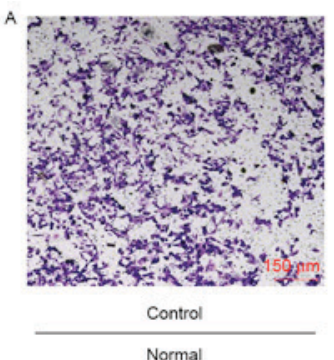

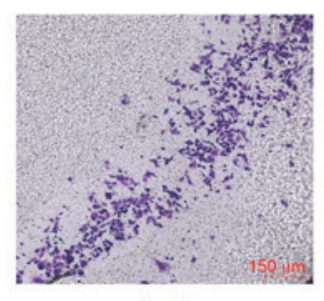

Control

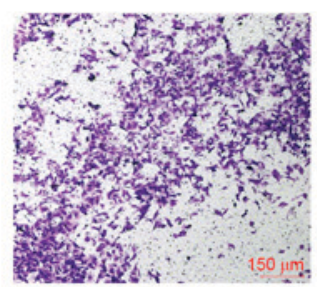

CXCL-8

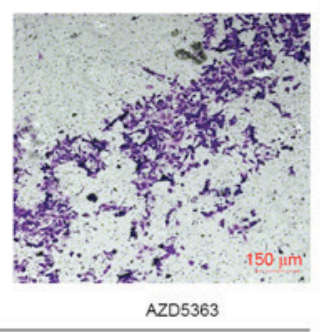

Hypoxia

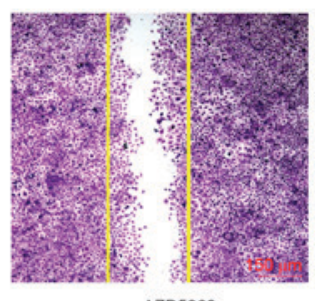

AZD5363

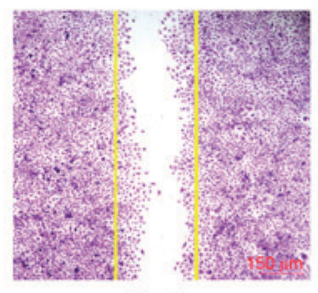
Control

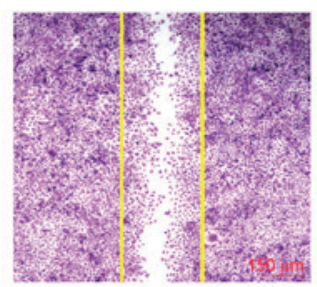

CXCL-8

Hypoxia

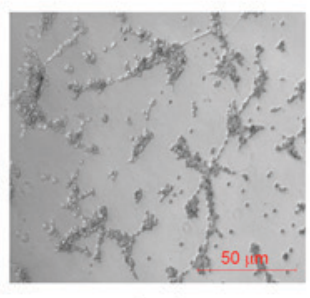

Control

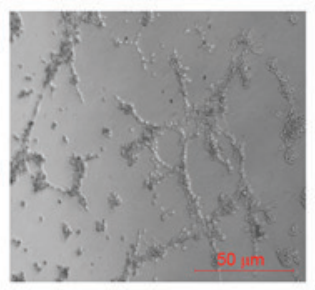

CXCL-8
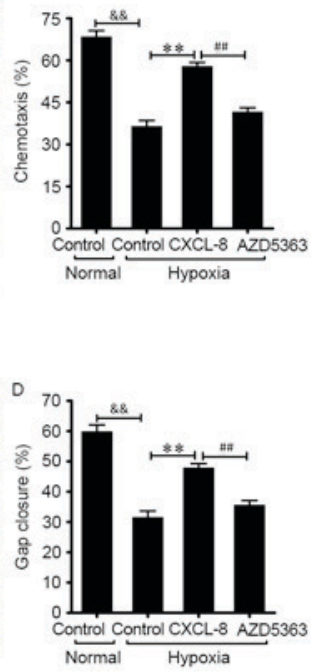

Hypoxia

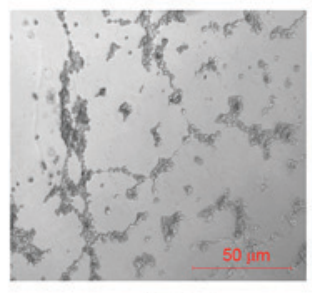

AZD5363

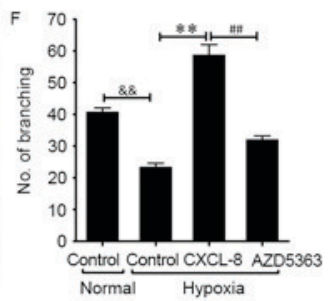

Normal

Figure 2. CXCL-8 promotes migration and tube formation in HUVECs during hypoxia. (A) Representative images of HUVEC migration in each treatment group after $24 \mathrm{~h}$ of culture. Scale bar, $150 \mu \mathrm{m}$. (B) The migration rate of HUVECs in each group. (C) Representative images of wound healing in each treatment group after $24 \mathrm{~h}$ of culture. Yellow lines indicate the wound scratch area at $0 \mathrm{~h}$. Scale bar, $150 \mu \mathrm{m}$. (D) Scratch closure rate of HUVECs in each group. (E) Representative images of tube formation in each treatment group after $12 \mathrm{~h}$ of culture. Scale bar, $150 \mu \mathrm{m}$. (F) Number of HUVEC tubes formed in each group. ${ }^{\& \&} \mathrm{P}<0.01$ vs. normal control group; ${ }^{* *} \mathrm{P}<0.01$ vs. hypoxia control group; ${ }^{\# \#} \mathrm{P}<0.01$ vs. hypoxia AZD5363 group. Data are expressed as mean \pm standard error of the mean $(\mathrm{n}=12)$. CXCL-8, C-X-C motif chemokine ligand 8; HUVEC, human umbilical vein endothelial cell; AZD5363, Akt inhibitor.
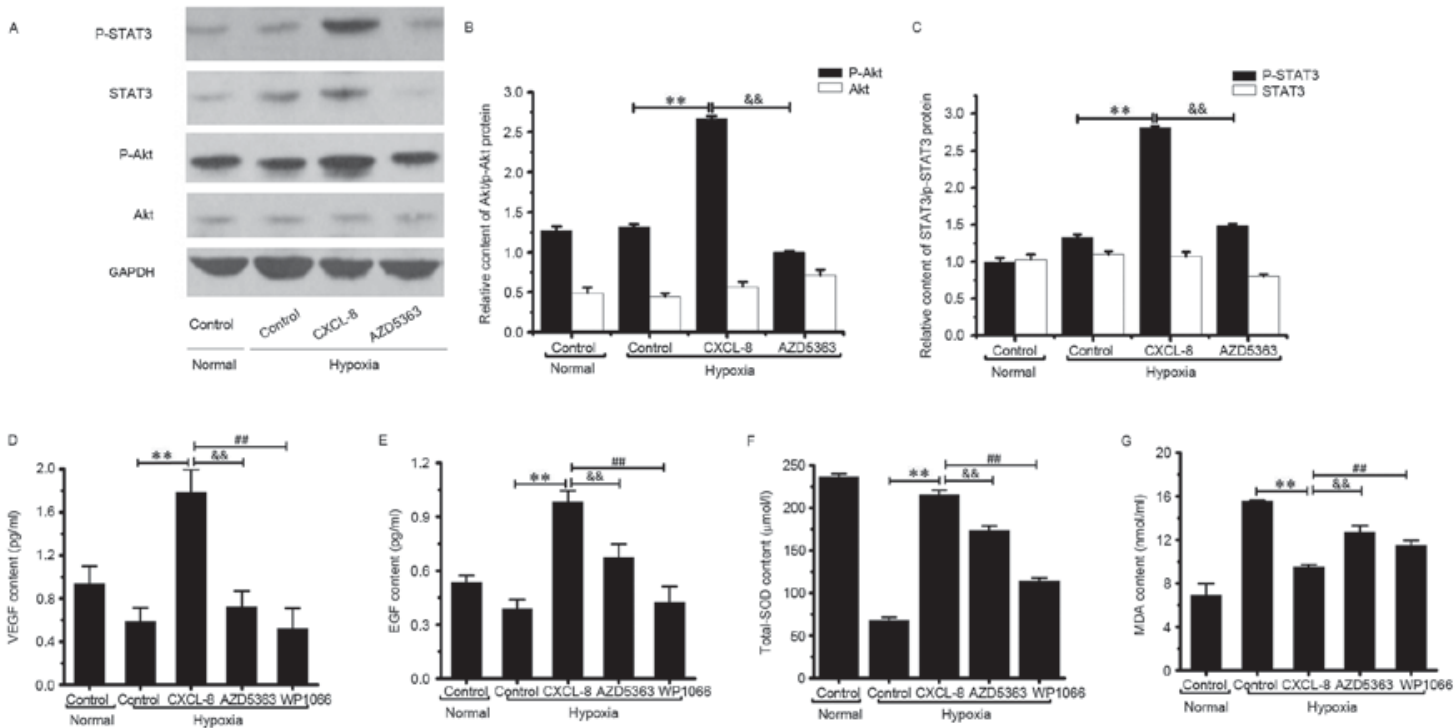

Figure 3. CXCL-8 alters the secretion of VEGF, EGF, total-SOD and MDA by promoting Akt and STAT3 phosphorylation. (A) Western blot analysis was used to detect the expression of Akt, p-Akt, STAT3 and p-STAT3. (B) Relative OD values of Akt/p-Akt (C) Relative OD values of STAT3/p-STAT3 protein. Concentrations of (D) VEGF, (E) EGF, (F) total-SOD and (G) MDA in the supernatants of HUVEC cells were detected by ELISA. ${ }^{\# \#} \mathrm{P}<0.01$ vs. hypoxia WP1066 group; ${ }^{* *} \mathrm{P}<0.01$ vs. hypoxia control group; \&\& $\mathrm{P}<0.01$ vs. hypoxia AZD5363 group $(\mathrm{n}=12)$. Data are expressed as the mean \pm standard error of the mean. CXCL-8, C-X-C motif chemokine ligand 8; HUVEC, human umbilical vein endothelial cell; VEGF, vascular endothelial growth factor; EGF, epidermal growth factor; SOD, superoxide dismutase; MDA, malondialdehyde; p-, phosphorylated; STAT3, signal transducer and activator of transcription 3; AZD5363, Akt inhibitor; OD, optical density. 
A
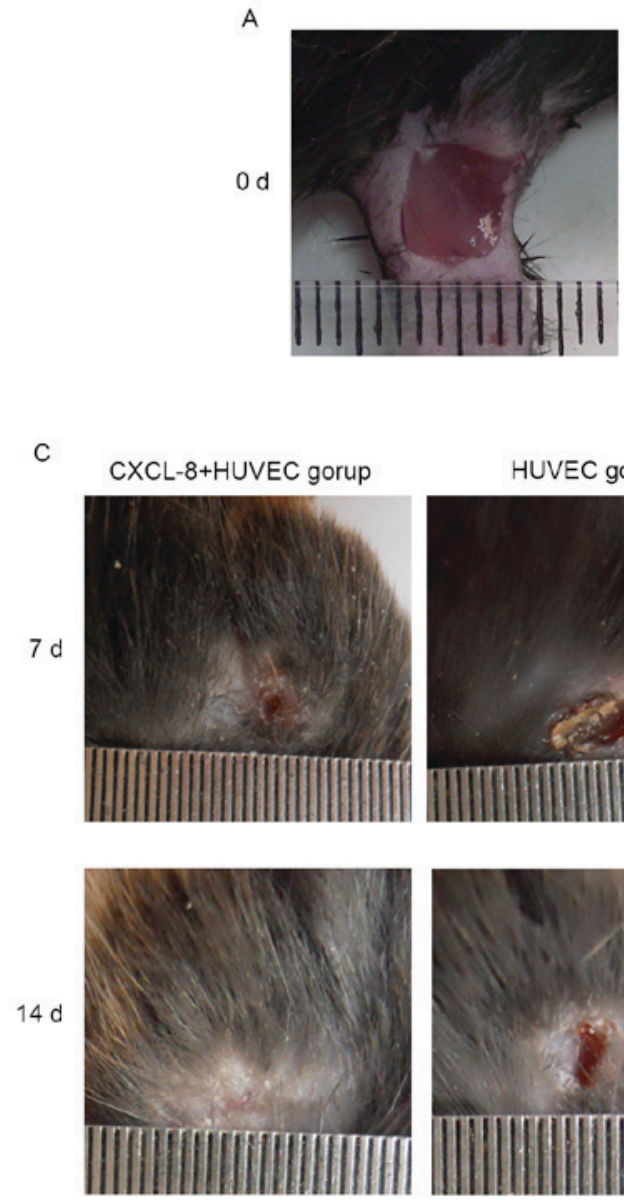

HUVEC gorup
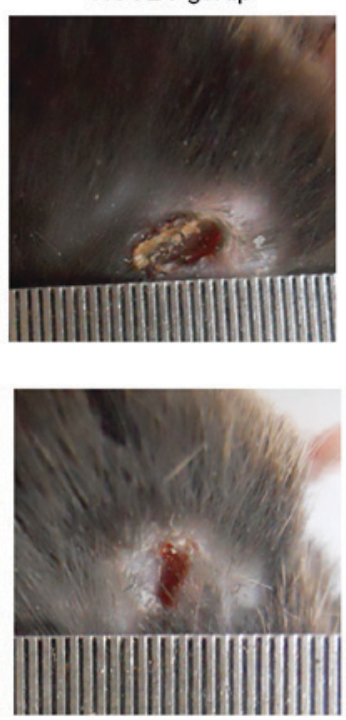

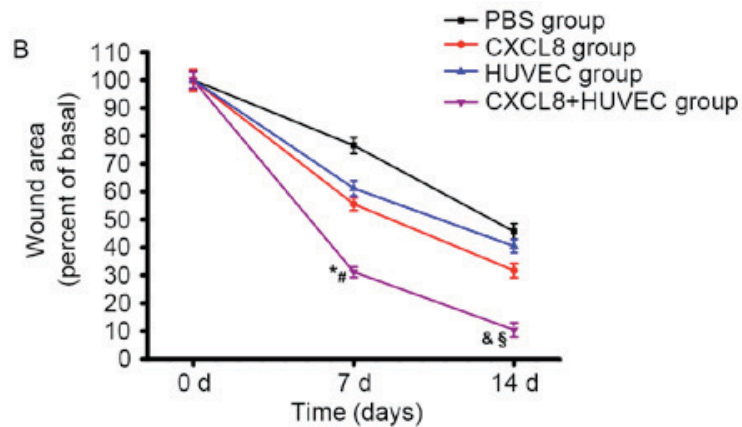

CXCL-8 gorup
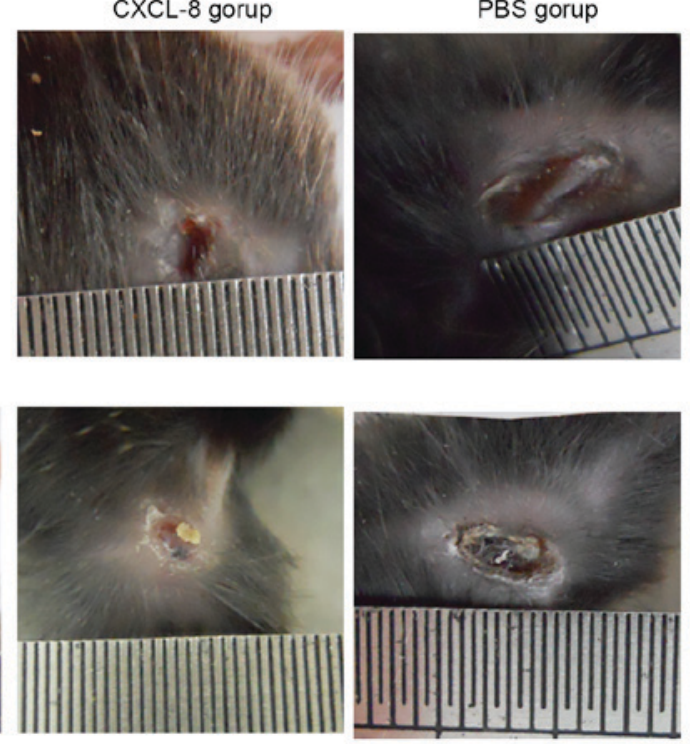

Figure 4. CXCL-8 promotes the healing of ischemic and hypoxic skin ulcers in a mouse model of hypoxic injury. (A) Representative image of the skin ulcer on day 0 post-surgery. (B) Healing rate of skin ulcers in each group. (C) Representative images of skin ulcers at 7 and 14 days following treatment in each group. ${ }^{*} \mathrm{P}<0.01$ vs. HUVEC group on day $7 ;{ }^{*} \mathrm{P}<0.01$ vs. CXCL-8 group on day $7 ;{ }^{\circledR} \mathrm{P}<0.01$ vs. HUVEC group on day $14 ;{ }^{\circledR} \mathrm{P}<0.01$ vs. CXCL-8 group on day 14 . Data are expressed as the mean \pm standard error of the mean $(\mathrm{n}=30)$. (Scale bar=1 mm). CXCL-8, C-X-C motif chemokine ligand 8; HUVEC, human umbilical vein endothelial cell; PBS, phosphate-buffered saline.

\section{Discussion}

The human body contains numerous cell types, including fibroblasts, vascular endothelial cells, endothelial progenitor cells and mesenchymal stem cells. These cells in particular, along with other stem cells, have a key role in the repair of wounds, inflammation and neurodegenerative diseases (26-28). During ischemia and hypoxia, oxygen free radicals and reactive oxygen species are generated by cells (29). Reactive oxygen species are responsible for cellular lipid peroxidation, resulting in the degradation of polyunsaturated fatty acids into MDA and other compounds. These cause toxic stress in cells and lead to intracellular damage, particularly to the endoplasmic reticulum, Golgi complex and other cell structures, thus reducing cellular activity (30). Therefore, reduced levels of SOD, glutathione and other anti-oxidant reductases leads to an increase in intracellular damage by oxygen free radicals (30). Vascular endothelial cells are essential for the process of angiogenesis, and are a promising cell type for use as a cell-based therapy in the repair of various types of ischemic and hypoxic tissue injury $(31,32)$. Stimulating the activity of vascular endothelial cells and other cell types during ischemia and hypoxia may reduce the damaging effects of hypoxia and aid in the repair of damaged tissue.
A previous study demonstrated that increasing the concentration of stromal cell-derived factor-1 locally within tissues may promote host cell homing to the area (33). Chemokines are a family of peptides that regulate cell proliferation and differentiation and promote chemotaxis. Chemokines are divided into four subfamilies (CC, $\mathrm{CXC}, \mathrm{CX}_{3} \mathrm{C}$ and $\mathrm{C}$ ) according to their structural motifs (33). Chemokine specificity and complexity of function is enabled by the variety of chemokines and receptors expressed by cells. Selective targeting of chemokine functions may be useful for the treatment of acute and chronic inflammation, angiogenesis, organ fibrosis, rheumatoid arthritis and atherosclerosis (34-36).

CXCL-8 binds with CXCR1/2 expressed on the plasma membrane of number of cells, including vascular endothelial cells and mesenchymal stem cells, which promotes stem cell homing and activates vascular endothelial cells during angiogenesis $(16,37)$. As the volume of a tumor increases, the center of the tumor becomes deficient in vessels, leading to hypoxia and other microenvironmental changes within the tumor tissue $(14,38)$. It has been observed that hypoxia stimulates HeLa cells to express high levels of CXCL-8, which subsequently promotes vascular endothelial cell homing and accelerates angiogenesis, leading to a reverse in the hypoxic 

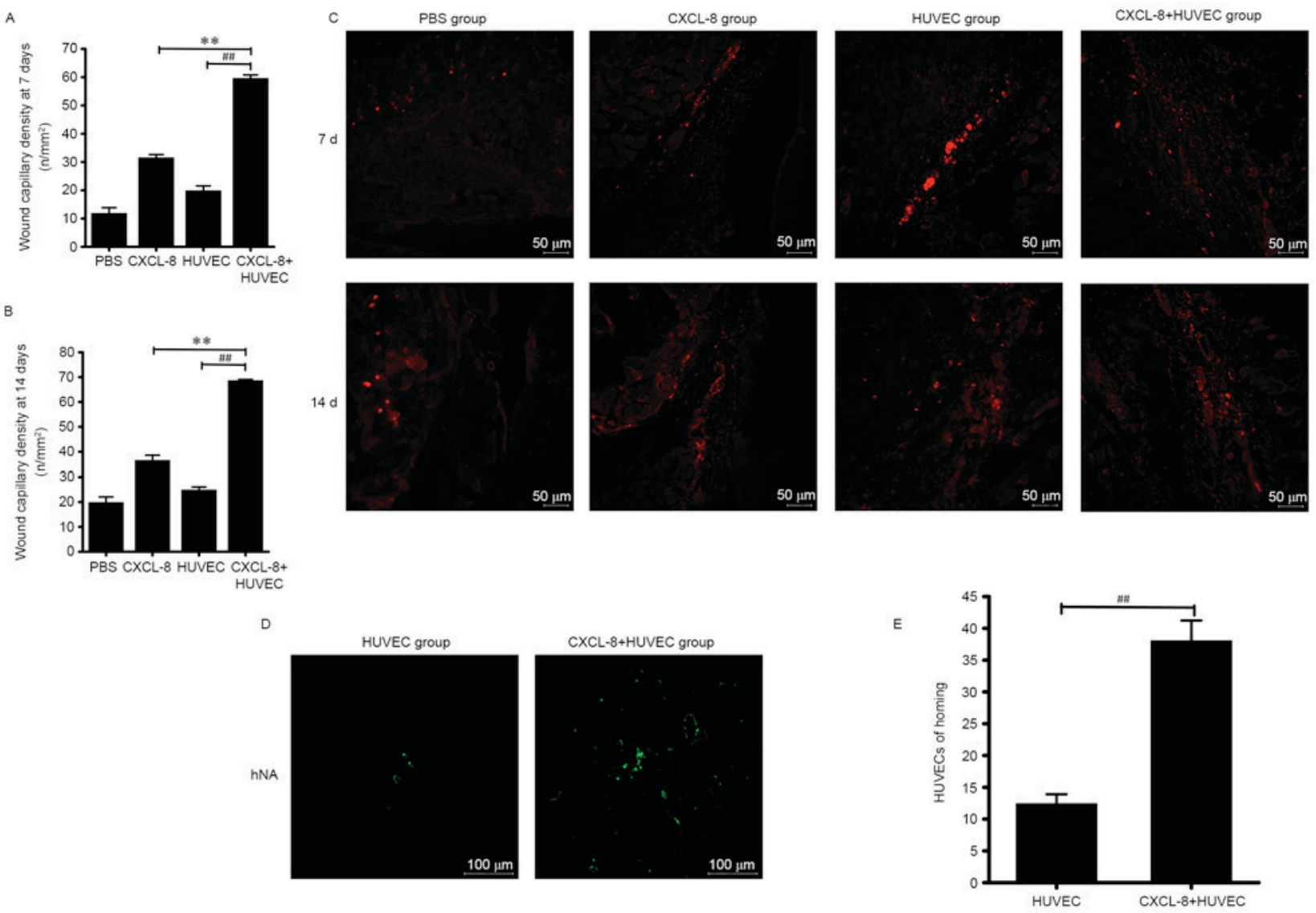

Figure 5. CXCL-8 increases vascular density and promotes HUVEC homing in hypoxic and ischemic skin ulcer tissue in a mouse model of hypoxic injury. Vascular density on days (A) 7 and (B) 14 post-surgery in each treatment group. (C) Representative images of cluster of differentiation 31 immunofluorescence staining (red) of skin ulcer tissue in each treatment group. Scale bar, $50 \mu \mathrm{m}$. (D) Representative images of hNA-positive HUVECs (green) on day 7 pot-surgery. Scale bar, $100 \mu \mathrm{m}$. (E) Number of hNA-stained homing HUVECs. ${ }^{* *} \mathrm{P}<0.01$ vs. CXCL-8 group; ${ }^{\# \prime} \mathrm{P}<0.01$ vs. HUVEC group. Data are expressed as the mean \pm standard error of the mean $(n=30)$. CXCL-8, C-X-C motif chemokine ligand 8; HUVEC, human umbilical vein endothelial cell; hNA human nuclear antigen; PBS, phosphate-buffered saline.

environment of the tumor tissue, increased tumor cell proliferation and inhibition of cell apoptosis (38). During the process of skin wound healing, macrophages secrete high levels of CXCL-8, which then stimulates the recruitment of fibroblasts, vascular endothelial cells, hair follicle stem cells and others to the skin defect area through binding to CXCR1/2 (39-41). CXCL-8 also promotes vascular endothelial cell adhesion, accelerates angiogenesis, increases the deposition of extracellular matrix and promotes wound healing, which further indicates the importance of CXCL-8 in wound healing $(39,40)$. Thus, the use of CXCL- 8 in cell-based treatments for hypoxic diseases may protect the transplanted cells, promote host cell homing and aid the repair of tissue damage.

In the current study, expression of SOD, EGF and VEGF in HUVECs in vitro was increased in the CXCL-8 group, relative to the hypoxia control group. In addition, AZD5363 and WP1066, as specific inhibitors of Akt and STAT3, respectively, caused the elevated expression of VEGF, EGF and SOD following CXCL-8 treatment to be decreased. This suggests that CXCL- 8 binding to CXCR1/2 on the surface of HUVECs promotes the secretion of VEGF, EGF and SOD through the phosphatidylinositol-4, 5-bisphosphate 3-kinase (PI3K)/Akt and Janus kinase (JAK)/STAT3 signal transduction pathways. In malignant glioma, it has been documented that the rapid growth of tumor tissue causes hypoxia due to a lack of blood vessels (14). Hypoxic conditions may promote the expression of CXCL-8 in malignant glial cells and in turn, CXCL-8 may promote the secretion of IL-6, VEGF and other inflammatory factors through the Akt-JAK-STAT pathway, thus inducing tumor metastasis and angiogenesis.

The expression of SOD and other anti-free radical enzymes, as observed in the CXCL- 8 group, may alleviate the free radical environment formed by hypoxia. SOD is an anti-oxidant enzyme that reduces the production of free radicals during hypoxia and repairs damaged lipids or DNA molecules (42). SOD may also reverse tissue injuries caused by reactive oxygen species and promote the recovery of tissue function (43). MDA is an end product of membrane lipid peroxidation and levels of MDA may be used to indicate the severity of cell stress (44). MDA itself causes additional membrane lipid peroxidation, leading to damages in the structure and function of the plasma membrane, organelles and other biological membrane structures, along with alterations in cell membrane permeability (45). Collectively, these effects disrupt the normal physiological and biochemical reactions within cells $(46,47)$. The current study demonstrated that levels of MDA were decreased in the CXCL-8 group. This indicates that CXCL-8 may have a key anti-oxidant role, potentially through its stimulatory effects on the expression of VEGF, EGF and SOD in vascular endothelial cells. Indeed 


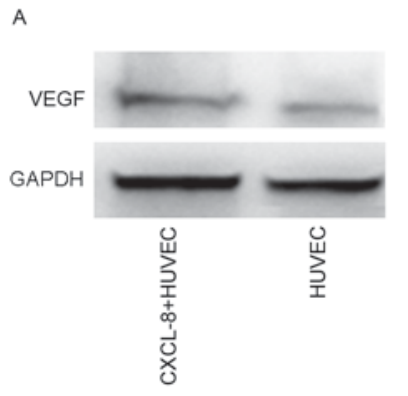

E

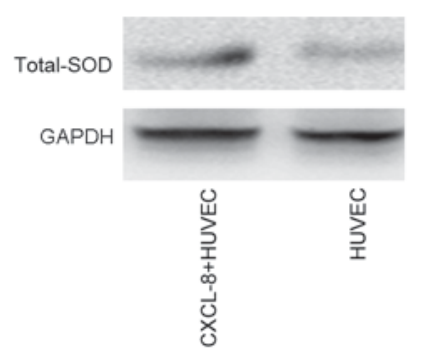

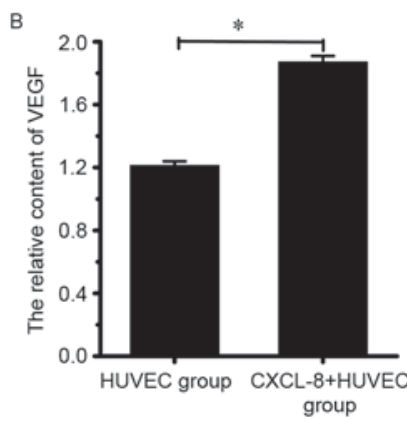

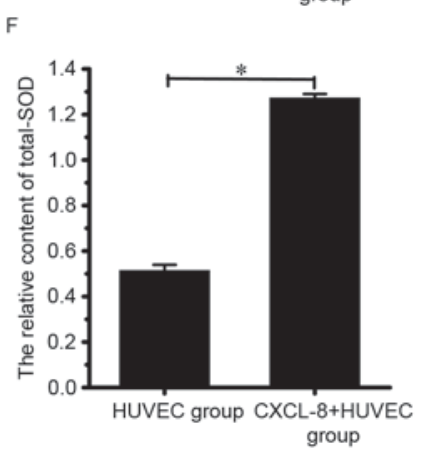

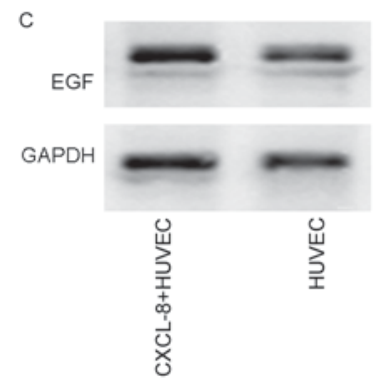
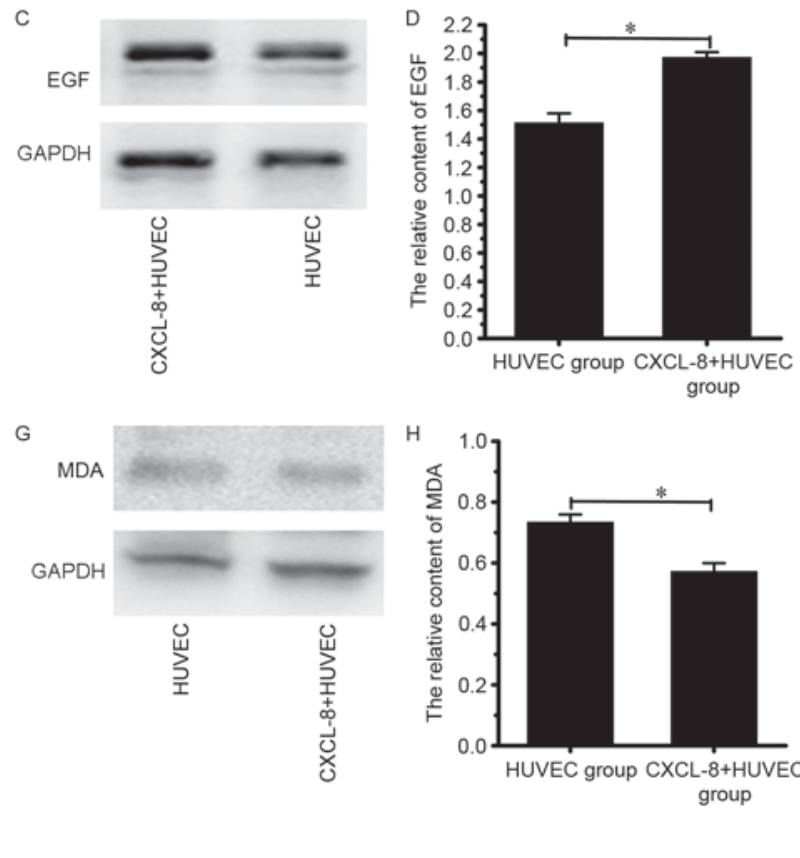

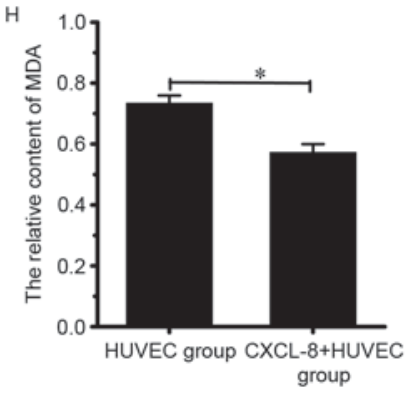

Figure 6. CXCL-8 alters the expression of VEGF, EGF total-SOD and MDA level in ischemic and hypoxic skin ulcer tissue in a mouse model of hypoxic injury. Levels of (A) VEGF, (C) EGF, (E) total-SOD and (G) MDA detected by western blot analysis. Relative expression of (B) VEGF (D) EGF (F) total-SOD and (H) MDA. GAPDH was used as an internal reference protein. ${ }^{*} \mathrm{P}<0.01$ vs. HUVEC group. Data are expressed as the mean \pm standard error of the mean ( $=30$ ). CXCL-8, C-X-C motif chemokine ligand 8; HUVEC, human umbilical vein endothelial cell; VEGF, vascular endothelial growth factor; EGF, epidermal growth factor; SOD, superoxide dismutase; MDA, malondialdehyde.

these factors are considered to promote degradation of MDA and have protective effects on biological membranes (48).

CXCR1/2, as the cognate receptor of CXCL-8, is a G-protein-coupled receptor (GPCR) that initiates a downstream signaling pathway (49). The binding of a chemokine to its appropriate GPCR induces the associated G-protein to exchange guanosine diphosphate for guanosine triphosphate (GTP). In the active state (GTP-bound), the G-protein dissociates into $G_{\alpha}$ and $G_{\beta}$ subunits, which then interact with various other proteins to continue the signaling pathway. G-protein activation triggers a series of reactions, including the cleavage of phosphatidylinositol 4,5-biphosphate into the second messenger molecules inositol trisphosphate (IP3) and diacylglycerol. IP3 induces the release of calcium ions from the endoplasmic reticulum, and thus the mobilization of calcium is a key indicator of chemotactic factor activity and subsequent cell homing (50).

The current study demonstrated that CXCL-8 promotes the expression of SOD and VEGF in HUVECs (51). A previous study documented that CXCL- 8 reduced damage to microfilaments and microtubules caused by reactive oxygen species, and promoted the chemotactic movement of HUVECs (52). In the current study, the effects of CXCL-8 on HUVEC cells were blocked by Akt inhibitors, resulting in reduced proliferation and migration, thus suggesting that Akt may serve a key role in the process of HUVEC migration (53). Although the PI3K/Akt and JAK/STAT3 signal transduction pathways are involved in the effects of CXCL-8 in vascular endothelial cells (53), the effects of CXCL-8 may also be transduced by extracellular signal-regulated kinase and other signaling molecules, though the associated mechanisms warrant further investigation $(53,54)$.
It has been previously documented that CXCL-12 (also known as stromal cell derived factor-1) may promote the migration of bone marrow mesenchymal stem cells (MSCs) (55), and the expression of VEGF and other cytokines in MSCs through Akt signaling, leading to enhanced angiogenesis and improvements in cardiac function during myocardial infarction (56). As CXCL-8 and CXCL-12 belong to the same protein family, the current study evaluated the roles of CXCL-8 in hypoxic disease, using a rat model of hypoxic ischemia in lower extremity wounds. Relative to the PBS control group, it was observed that the ischemic wound area was reduced by CXCL- 8 treatment, and the rate of wound healing was significantly increased. Immunofluorescence staining also demonstrated that the expression of SOD and CD31 (a vascular endothelial cell marker) were increased in the skin ulcer tissue following CXCL- 8 treatment. This indicated that CXCL- 8 may promote the expression of anti-oxidant proteins and protect vascular endothelial cells against damage by free radicals in hypoxic tissue. CXCL-8 may also promote homing of vascular endothelial cells to the skin ulcer area to increase angiogenesis, reduce hypoxia and accelerate ulcer healing. The healing of skin wounds involves the secretion of numerous cytokines and interactions between fibroblasts, vascular endothelial cells and various other cell types (39). As the present study evaluated the effect of CXCL-8 on only vascular endothelial cells, studies into the effects of CXCL-8 on other cell types are warranted. Nevertheless, results of the current study indicate that the use of CXCL-8 to activate protective mechanisms within host cells and recruit cells in the process of tissue repair may aid to improve anti-hypoxia cell-based therapies.

In conclusion, CXCL-8 may stimulate HUVECs through a paracrine signaling pathway to inhibit damage caused by 
hypoxia and promote angiogenesis. Currently, the use of MSCs and other stem cells in the repair of human tissue damage has a range of potential applications $(57,58)$. The use of CXCL-8 in cell-based therapies may promote cell homing, protect cells, promote angiogenesis and accelerate the repair of damaged tissue (40). Future studies are now warranted in animal models of ischemic heart disease and diabetic neuropathy, to determine the effects of MSCs overexpressing CXCL- 8 and the corresponding mechanisms of action, particularly regarding ischemic disease. Results from the present and future studies may promote the use of cell-based therapies for the clinical treatment of ischemic and hypoxic diseases.

\section{Acknowledgements}

The present study was supported by the National Science Foundation of China (grant no. 81541137), the Research Project of Heilongjiang Provincial Education Department (grant no. 12541901) and the Fund Project of Qiqihar Medical University (grant nos. QY2014Z-09 and QY2015B-04).

\section{References}

1. Kawarada O, Yasuda S, Noguchi T, Anzai T and Ogawa H: Renovascular heart failure: Heart failure in patients with atherosclerotic renal artery disease. Cardiovasc Interv Ther 31: 171-182, 2016.

2. Lubrano V, Venturi E, Balzan S, Baldi S and Natali A: Impact of risk factor for atherosclerosis on microvascular endothelial function: An in vitro study. Theor Biol Forum 108: 75-88, 2015.

3. Cahill PA and Redmond EM: Vascular endothelium-Gatekeeper of vessel health. Atherosclerosis 248: 97-109, 2016.

4. McGill HC Jr, McMahan CA, Zieske AW, Sloop GD, Walcott JV Troxclair DA, Malcom GT, Tracy RE, Oalmann MC and Strong JP: Associations of coronary heart disease risk factors with the intermediate lesion of atherosclerosis in youth. the pathobiological determinants of atherosclerosis in youth (PDAY) research group. Arterioscler Thromb Vasc Biol 20: 1998-2004, 2000.

5. Eder L and Gladman DD: Atherosclerosis in psoriatic disease: Latest evidence and clinical implications. Ther Adv Musculoskelet Dis 7: 187-195, 2015.

6. Guimarães JM, Clarke P, Tate D, Coeli CM, Griep RH, Fonseca MJ, Santos IS, Melo EC and Chor D: Social mobility and subclinical atherosclerosis in a middle-income country: Association of intra- and inter-generational social mobility with carotid intima-media thickness in the Brazilian Longitudinal study of adult health (ELSA-Brasil). Soc Sci Med 169: 9-17, 2016.

7. Karagkiozaki V, Logothetidis S and Pappa AM: Nanomedicine for atherosclerosis: Molecular imaging and treatment. J Biomed Nanotechnol 11: 191-210, 2015.

8. Garcia-González V, Delgado-Coello B, Pérez-Torres A and Mas-Oliva J: Reality of a vaccine in the prevention and treatment of atherosclerosis. Arch Med Res 46: 427-437, 2015.

9. Lönn ME, Dennis JM and Stocker R: Actions of 'antioxidants' in the protection against atherosclerosis. Free Radic Biol Med 53 863-884, 2012

10. Lusis AJ: Atherosclerosis. Nature 407: 233-241, 2000.

11. Kariminekoo S, Movassaghpour A, Rahimzadeh A, Talebi M, Shamsasenjan K and Akbarzadeh A: Implications of mesenchymal stem cells in regenerative medicine. Artif Cells Nanomed Biotechnol 44: 749-757, 2016

12. Suh $\mathrm{H}$ : Tissue restoration, tissue engineering and regenerative medicine. Yonsei Med J 41: 681-684, 2000.

13. Helmy KY, Patel SA, Silverio K, Pliner L and Rameshwar P: Stem cells and regenerative medicine: Accomplishments to date and future promise. Ther Deliv 1: 693-705, 2010.

14. Piperi C, Samaras V, Levidou G, Kavantzas N, Boviatsis E, Petraki K, Grivas A, Barbatis C, Varsos V, Patsouris E and Korkolopoulou P: Prognostic significance of IL-8-STAT-3 pathway in astrocytomas: Correlation with IL-6, VEGF and microvessel morphometry. Cytokine 55: 387-395, 2011.
15. Ogura M, Takeuchi H, Kawakubo H, Nishi T, Fukuda K, Nakamura R, Takahashi T, Wada N, Saikawa Y, Omori T, et al: Clinical significance of CXCL-8/CXCR-2 network in esophageal squamous cell carcinoma. Surgery 154: 512-520, 2013.

16. Yang DF, Huang H, Guan S, Zhu HF, Zhang CC, Zhao JP, Fang HJ and Lavoie JP: Interleukin (IL)-4 promotion of CXCL-8 gene transcription is mediated by ERK1/2 pathway in human pulmonary artery endothelial cells. Mol Immunol 48: 1784-1792, 2011.

17. Wang J, Wang Y, Wang S, Cai J, Shi J, Sui X, Cao Y, Huang W, Chen X, Cai Z, et al: Bone marrow-derived mesenchymal stem cell-secreted IL-8 promotes the angiogenesis and growth of colorectal cancer. Oncotarget 6: 42825-42837, 2015.

18. Liu H, Qiu H, Xiao Q and Le W: Chronic hypoxia-induced autophagy aggravates the neuropathology of alzheimer's disease through ampk-mTOR signaling in the APPSwe/PS1DE9 mouse model. J Alzheimers Dis 48: 1019-1032, 2015.

19. Vaughan MB, Odejimi TD, Morris TL, Sawalha D and Spencer CL: A new bioassay identifies proliferation ratios of fibroblasts and myofibroblasts. Cell Biol Int 38: 981-986, 2014.

20. Shen L, Zeng W, Wu YX, Hou CL, Chen W, Yang MC, Li L, Zhang YF and Zhu $\mathrm{CH}$ : Neurotrophin-3 accelerates wound healing in diabetic mice by promoting a paracrine response in mesenchymal stem cells. Cell Transplant 22: 1011-1021, 2013.

21. Hou C, Shen L, Huang Q, Mi J, Wu Y, Yang M, Zeng W, Li L, Chen $\mathrm{W}$ and Zhu C: The effect of heme oxygenase-1 complexed with collagen on MSC performance in the treatment of diabetic ischemic ulcer. Biomaterials 34: 112-120, 2013.

22. Barcelos LS, Duplaa C, Kränkel N, Graiani G, Invernici G, Katare R, Siragusa M, Meloni M, Campesi I, Monica M, et al: Human $\mathrm{CD}_{133^{+}}$progenitor cells promote the healing of diabetic ischemic ulcers by paracrine stimulation of angiogenesis and activation of Wnt signaling. Circ Res 104: 1095-1102, 2009.

23. He S, Shen L, Wu Y, Li L, Chen W, Hou C, Yang M, Zeng W and Zhu C: Effect of brain-derived neurotrophic factor on mesenchymal stem cell-seeded electrospinning biomaterial for treating ischemic diabetic ulcers via milieu-dependent differentiation mechanism. Tissue Eng Part A 21: 928-938, 2015.

24. Wang Z, Zhao X and Gong X: Costunolide induces lung adenocarcinoma cell line A549 cells apoptosis through ROS (reactive oxygen species)-mediated endoplasmic reticulum stress. Cell Biol Int 40: 289-297, 2016.

25. Sheng L, Mao X, Yu Q and Yu D: Effect of the PI3K/AKT signaling pathway on hypoxia-induced proliferation and differentiation of bone marrow-derived mesenchymal stem cells. Exp Ther Med 13: 55-62, 2017.

26. Liu Y and Deng W: Reverse engineering human neurodegenerative disease using pluripotent stem cell technology. Brain Res 1638: 30-41, 2016.

27. André EM, Passirani C, Seijo B, Sanchez A and MonteroMenei CN: Nano and microcarriers to improve stem cell behaviour for neuroregenerative medicine strategies: Application to Huntington's disease. Biomaterials 83: 347-362, 2016.

28. Schenke-Layland K and Walles H: Strategies in tissue engineering and regenerative medicine. Biotechnol J 8: 278-279, 2013.

29. Tuleta I, Franca CN, Wenzel D, Fleischmann B, Nickenig G, Werner N and Skowasch D: Hypoxia-induced endothelial dysfunction in apolipoprotein E-deficient mice; effects of infliximab and L-glutathione. Atherosclerosis 236: 400-410, 2014.

30. Görlach A, Dimova EY, Petry A, Martínez-Ruiz A, Hernansanz-Agustín P, Rolo AP, Palmeira CM and Kietzmann T: Reactive oxygen species, nutrition, hypoxia and diseases: Problems solved? Redox Biol 6: 372-385, 2015.

31. Hung HS, Chen HC, Tsai CH and Lin SZ: Novel approach by nanobiomaterials in vascular tissue engineering. Cell Transplant 20: 63-70, 2011.

32. Shestopalov IA and Zon LI: Stem cells: The right neighbour. Nature 481: 453-455, 2012.

33. Dona E, Barry JD, Valentin G, Quirin C, Khmelinskii A, Kunze A, Durdu S, Newton LR, Fernandez-Minan A, Huber W, et al: Directional tissue migration through a self-generated chemokine gradient. Nature 503: 285-289, 2013.

34. Lusso P: Chemokines and HIV: The first close encounter. Front Immunol 6: 294, 2015.

35. Hartmann P, Schober A and Weber C: Chemokines and microRNAs in atherosclerosis. Cell Mol Life Sci 72: 3253-3266, 2015. 
36. Rees PA, Greaves NS, Baguneid M and Bayat A: Chemokines in wound healing and as potential therapeutic targets for reducing cutaneous scarring. Adv Wound Care (New Rochelle) 4: 687-703, 2015.

37. Li L, Yang M, Wang C, Zhao Q, Liu J, Zhan C, Liu Z, Li X, Wang W and Yang X: Effects of cytokines and chemokines on migration of mesenchymal stem cells following spinal cord injury. Neural Regen Res 7: 1106-1112, 2012.

38. Liu LB, Xie F, Chang KK, Li MQ, Meng YH, Wang XH, Li H, $\mathrm{Li}$ DJ and Yu JJ: Hypoxia promotes the proliferation of cervical carcinoma cells through stimulating the secretion of IL-8. Int J Clin Exp Pathol 7: 575-583, 2014.

39. Sun BK, Siprashvili Z and Khavari PA: Advances in skin grafting and treatment of cutaneous wounds. Science 346: 941-945, 2014

40. Eming SA, Martin P and Tomic-Canic M: Wound repair and regeneration: Mechanisms, signaling, and translation. Sci Transl Med 6: 265sr6, 2014.

41. Singh K, Agrawal NK, Gupta SK, Sinha P and Singh K: Increased expression of TLR9 associated with pro-inflammatory S100A8 and IL-8 in diabetic wounds could lead to unresolved inflammation in type 2 diabetes mellitus (T2DM) cases with impaired wound healing. J Diabetes Complications 30: 99-108, 2016.

42. Kalyanaraman B: Teaching the basics of redox biology to medical and graduate students: Oxidants, antioxidants and disease mechanisms. Redox Biol 1: 244-257, 2013.

43. Wang L, Duan Q, Wang T, Ahmed M, Zhang N, Li Y, Li L and Yao X: Mitochondrial respiratory chain inhibitors involved in ROS production induced by acute high concentrations of iodide and the effects of SOD as a protective factor. Oxid Med Cell Longev 2015: 217670, 2015.

44. Schmid-Siegert E, Stepushchenko O, Glauser G and Farmer EE: Membranes as structural antioxidants: Recycling of malondialdehyde to its source in oxidation-sensitive chloroplast fatty acids. J Biol Chem 291: 13005-13013, 2016.

45. Asmat U, Abad K and Ismail K: Diabetes mellitus and oxidative stress-A concise review. Saudi Pharm J 24: 547-553, 2016.

46. Karunakaran U and Park KG: A systematic review of oxidative stress and safety of antioxidants in diabetes: Focus on islets and their defense. Diabetes Metab J 37: 106-112, 2013.

47. Maritim AC, Sanders RA and Watkins JB III: Diabetes, oxidative stress and antioxidants: A review. J Biochem Mol Toxicol 17: 24-38, 2003

48. Pisoschi AM and Pop A: The role of antioxidants in the chemistry of oxidative stress: A review. Eur J Med Chem 97: 55-74, 2015.
49. Liou JW, Chang FT, Chung Y, Chen WY, Fischer WB and Hsu HJ: In silico analysis reveals sequential interactions and protein conformational changes during the binding of chemokine CXCL-8 to its receptor CXCR1. PLoS One 9: e94178, 2014.

50. Greenberg ML, Yu Y, Leverrier S, Zhang SL, Parker I and Cahalan MD: Orail function is essential for T cell homing to lymph nodes. J Immunol 190: 3197-3206, 2013.

51. Murayama C, Kaji A, Miyauchi K, Matsui M, Miyamoto A and Shimizu T: Effect of VEGF (vascular endothelial growth factor) on expression of IL-8 (interleukin-8), IL-1beta and their receptors in bovine theca cells. Cell Biol Int 34: 531-536, 2010.

52. Shi D, Li X, Chen H, Che N, Zhou S, Lu Z, Shi S and Sun L: High level of reactive oxygen species impaired mesenchymal stem cell migration via overpolymerization of F-actin cytoskeleton in systemic lupus erythematosus. Pathol Biol (Paris) 62: 382-390, 2014.

53. Li MQ, Luo XZ, Meng YH, Mei J, Zhu XY, Jin LP and Li DJ: CXCL8 enhances proliferation and growth and reduces apoptosis in endometrial stromal cells in an autocrine manner via a CXCR1-triggered PTEN/AKT signal pathway. Hum Reprod 27: 2107-2116, 2012

54. Lin K, Fang S, Cai B, Huang X, Zhang X, Lu Y, Zhang W and Wei E: ERK/Egr-1 signaling pathway is involved in CysLT2 receptor-mediated IL-8 production in HEK293 cells. Eur J Cell Biol 93: 278-288, 2014.

55. Wynn RF, Hart CA, Corradi-Perini C, O'Neill L, Evans CA, Wraith JE, Fairbairn LJ and Bellantuono I: A small proportion of mesenchymal stem cells strongly expresses functionally active CXCR4 receptor capable of promoting migration to bone marrow. Blood 104: 2643-2645, 2004.

56. Tang J, Wang J, Zheng F, Kong X, Guo L, Yang J, Zhang L and Huang Y: Combination of chemokine and angiogenic factor genes and mesenchymal stem cells could enhance angiogenesis and improve cardiac function after acute myocardial infarction in rats. Mol Cell Biochem 339: 107-118, 2010.

57. Tevlin R, Walmsley GG, Marecic O, Hu MS, Wan DC and Longaker MT: Stem and progenitor cells: Advancing bone tissue engineering. Drug Deliv Transl Res 6: 159-173, 2016.

58. Martino MM, Maruyama K, Kuhn GA, Satoh T, Takeuchi O, Müller R and Akira S: Inhibition of IL-1R1/MyD88 signaling promotes mesenchymal stem cell-driven tissue regeneration. Nat Commun 7: 11051, 2016. 